\title{
BER ENHANCEMENT OF MIMO-CDMA BASED ON SPACE-TIME BLOCK CODES
}

\author{
P. Sreesudha ${ }^{1}$, M. Vijaya Lakshmi ${ }^{2}$ \\ ${ }^{1}$ Student M.Tech, Dept. of ECE, GNITS, Hyderabad, India \\ sree.sudha38@gmail.com \\ ${ }^{2}$ Associate Professor, Dept. of ECE, GNITS, Hyderabad, India \\ mvlakshmi_gnitseyahoo.co.in
}

\begin{abstract}
Now a days, the demand for wireless communication systems with high data rates and high capacity has dramatically increased. CDMA (Code Division Multiple access) plays an important role in modern wireless communication systems. MIMO refers to links with multiple antennas at the transmitter and receiver side. CDMA with MIMO is a very promising technique beyond $3 G$ and $4 G$ wireless communications. The BER performance of MIMO-CDMA system depends on its spreading strategy. In this paper MIMO-CDMA system is designed with STBC (Space-Time Block Code) matrices for spreading. The proposed technique outperforms the tdesign permutation spreading method and also the conventional method. Simulation results shows that gain improvement with STBC approach as compared to other existing techniques.
\end{abstract}

\section{KEYWORDS}

CDMA, BER performance, MIMO-CDMA, STBC

\section{INTRODUCTION}

CDMA is an underlying technology used in $3 \mathrm{G}$ and $2 \mathrm{G}$. Wireless systems with multiple transmit and receive antennas systems are an important part of discussions on future wireless communication systems. In rich scattering environments, these systems offer large capacity gains [1].

In MIMO-CDMA to improve the bit error rate performance parity bit selected spreading sequences are introduced initially [2], in this linear block coding technique is used. In that Parity bits are used to select the spreading sequence from a set of orthogonal spreading sequences. The information bits are then spread by this spreading sequence. At the receiver, the spreading code employed is determined from the outputs of the filters that are matched to each spreading sequence. The information bits are then determined from the output of the specific matched filter. Error correction is then performed by assuming that the parity bits are correct. So compared to conventional system BER is improved, but some sort of self interference occurred due to summing of all transmitted signals. T-designs spreading permutations scheme was introduced later to improve the BER performance in MIMO-CDMA, this technique improves the BER compared to block coding approach but additional complexity introduces [3].

Recently, there are a large number of research papers on use of multiple input multiple output (MIMO) in CDMA transmission to combat multipath fading and provide spatial diversity. David Bracewell, et al. (Eds): AIAA 2011,CS \& IT 03, pp. 21-26 , 2011.

(C) CS \& IT-CSCP 2011

DOI : 10.5121/csit.2011.1303 
Among them, space time spreading (STS) and space time block coding (STBC) are the most efficient method due to its provision of full spatial diversity and simple linear decoder in [4]. The combination of space-time block coding (STBC) and direct-sequence code-division multiple access (DS-CDMA) has the potential to increase the performance of multiple users in a cellular network.

The paper is organized as follows: In section 2, MIMO-CDMA system is designed with conventional approach, In Section 3, t-design permutation spreading is implemented, In Section 4, Space-Time Block Code technique is used for spreading permutation of MIMO-CDMA system, In section 5, Simulation results are discussed, and the paper is concluded in Section 6.

\section{CONVENTIONAL MIMO-CDMA}

Third generation cellular systems employ direct sequence code-division multiple-access (DSCDMA) as the channel access scheme. In conventional MIMO-CDMA systems, unique codes are assigned per user.

In conventional MIMO-CDMA, each user use a different spreading code for each transmitting antenna. In conventional MIMO-CDMA system the spreading waveforms are fixed.

$$
\mathrm{W}_{\mathrm{mi}}=\mathrm{C}_{\mathrm{mi}}(\mathrm{t}-\mathrm{nT}) \text {------------------- (1) }
$$

Where $\mathrm{W}_{\mathrm{mi}}$ is the spreading waveform for $\mathrm{i}$ th data stream of user $\mathrm{m}$ and $\mathrm{C}_{\mathrm{mi}}$ is the orthogonal spreading sequence.

Each antenna uses one spreading waveform, for $\mathrm{N}_{\mathrm{t}}=4$ antennas system 4 spreading waveforms are required per user. At the receiver side, the received data is given bank of matched filters. Based on the matched filters decision, the transmitted data is estimated.

\section{MIMO-CDMA WITH T-DESIGNS}

MIMO-CDMA with Parity bit selected spreading is discussed in [2]. In parity bit selected spreading sequence technique, based on the calculated parity bits the spreading waveform is selected for each antenna. In this approach, for each user $2^{(n-k)}$ spreading sequences will be assigned. Where $n-k$ is the number of parity bits of the code.

The system MIMO-CDMA with t-design permutation spreading is similar to parity bit selected spreading. In this technique, all possible message vectors are divided in to cosets and depending on which coset that messages comes then the corresponding permutation of spreading waveforms are assigned for each antenna in to groups.

Now $\mathrm{M}$ is a set of all possible message vectors, contains 16 elements. $\mathrm{M}$ is divided into 8 possible cosets. The MIMO-CDMA system is designed with $\mathrm{N}_{\mathrm{t}}=\mathrm{N}_{\mathrm{r}}=4$ antennas, and $\mathrm{N}=8$. On signalling interval, the message to be transmitted is $\left\{\mathrm{m}_{1}, \mathrm{~m}_{2}, \ldots \mathrm{m}_{\mathrm{Nt}}\right\}$.

The cosets are $\mathrm{M} 1=\left\{\begin{array}{lll}0000 & 1111\end{array}\right\}, \mathrm{M} 2=\left\{\begin{array}{ll}0001 & 1110\end{array}\right\}, \mathrm{M} 3=\left\{\begin{array}{lll}0010 & 1101\end{array}\right\}, \quad \mathrm{M} 4=\left\{\begin{array}{ll}0011 & 1100\end{array}\right\}$ $M 5=\{01001011\}, M 6=\{01011010\}, M 7=\{01101001\}, M 8=\left\{\begin{array}{lll}0111 & 1000\end{array}\right\}$.

And the spreading sequences are assigned to the antennas as shown in TABLE I. for example, if the message comes from M1, then spreading waveforms for four antennas are $c_{1}, c_{3}, c_{5}$ and $\mathrm{c}_{7}$ correspondingly, that is shown in the first row of the TABLE I.

The received vector at the output of matched filters of the system is

$$
\begin{array}{cc}
r_{j l}=\left\{b_{i} \sqrt{E_{b} / N_{r}} \alpha_{i j}+n_{j l}\right. & \text { If } \mathrm{w}_{\mathrm{i}}(\mathrm{t})=\mathrm{c}_{\mathrm{l}}(\mathrm{t}) \\
\left\{n_{j l}\right. & \text { Otherwise }
\end{array}
$$




\begin{tabular}{|c|c|l|l|l|l|}
\hline Coset & $\begin{array}{c}\text { Message } \\
\text { Vectors }\end{array}$ & $w_{1}(t)$ & $w_{2}(t)$ & \multicolumn{1}{|c|}{$w_{3}(t)$} & \multicolumn{1}{|c|}{$w_{4}(t)$} \\
\hline $\mathrm{M}_{1}$ & $\begin{array}{l}0000 \\
1111\end{array}$ & $\mathrm{C}_{1}(\mathrm{t})$ & $\mathrm{C}_{3}(\mathrm{t})$ & $\mathrm{C}_{5}(\mathrm{t})$ & $\mathrm{C}_{7}(\mathrm{t})$ \\
\hline $\mathrm{M}_{2}$ & $\begin{array}{l}0001 \\
1110\end{array}$ & $\mathrm{C}_{8}(\mathrm{t})$ & $\mathrm{C}_{1}(\mathrm{t})$ & $\mathrm{C}_{4}(\mathrm{t})$ & $\mathrm{C}_{5}(\mathrm{t})$ \\
\hline $\mathrm{M}_{3}$ & $\begin{array}{l}0010 \\
1101\end{array}$ & $\mathrm{C}_{2}(\mathrm{t})$ & $\mathrm{C}_{4}(\mathrm{t})$ & $\mathrm{C}_{3}(\mathrm{t})$ & $\mathrm{C}_{8}(\mathrm{t})$ \\
\hline $\mathrm{M}_{4}$ & $\begin{array}{l}0011 \\
1100\end{array}$ & $\mathrm{C}_{5}(\mathrm{t})$ & $\mathrm{C}_{2}(\mathrm{t})$ & $\mathrm{C}_{6}(\mathrm{t})$ & $\mathrm{C}_{3}(\mathrm{t})$ \\
\hline $\mathrm{M}_{5}$ & $\begin{array}{l}0100 \\
1011\end{array}$ & $\mathrm{C}_{6}(\mathrm{t})$ & $\mathrm{C}_{7}(\mathrm{t})$ & $\mathrm{C}_{1}(\mathrm{t})$ & $\mathrm{C}_{4}(\mathrm{t})$ \\
\hline $\mathrm{M}_{6}$ & $\begin{array}{l}0101 \\
1010\end{array}$ & $\mathrm{C}_{3}(\mathrm{t})$ & $\mathrm{C}_{6}(\mathrm{t})$ & $\mathrm{C}_{8}(\mathrm{t})$ & $\mathrm{C}_{1}(\mathrm{t})$ \\
\hline $\mathrm{M}_{7}$ & $\begin{array}{l}0110 \\
1001\end{array}$ & $\mathrm{C}_{7}(\mathrm{t})$ & $\mathrm{C}_{8}(\mathrm{t})$ & $\mathrm{C}_{2}(\mathrm{t})$ & $\mathrm{C}_{6}(\mathrm{t})$ \\
\hline $\mathrm{M}_{8}$ & $\begin{array}{l}0111 \\
1000\end{array}$ & $\mathrm{C}_{4}(\mathrm{t})$ & $\mathrm{C}_{5}(\mathrm{t})$ & $\mathrm{C}_{7}(\mathrm{t})$ & $\mathrm{C}_{2}(\mathrm{t})$ \\
\hline
\end{tabular}

\section{SPACE-Time Block CODE APPROACH}

The MIMO-CDMA system employing STBC permutation spreading [5] is shown in Fig 1. The input bit stream is converted into $\mathrm{N}_{\mathrm{t}}$ parallel data streams. And these bits are given to spreading sequence selector that selects $\mathrm{N}_{\mathrm{t}}$ spreading waveforms, then these data bits are modulated with BPSK modulation, then each bit is spread by using spreading waveform. On a given signalling interval $\mathrm{N}_{\mathrm{t}}$ spreading waveforms will be selected from $\mathrm{N}$ orthogonal spreading waveforms.

And at the receiver side, the output of each antenna is given to a bank of matched filters, and according to matched filter decision, the transmitted data is estimated.

The spreading assignment is done based on $8 \times 8 \mathrm{STBC}$ matrix. And the matrix [6] is given as:

$\left[\begin{array}{ccccccccc}\mathrm{c}_{1} & \mathrm{c}_{2} & \mathrm{c}_{3} & \mathrm{c}_{4} & \mathrm{c}_{5} & \mathrm{c}_{6} & \mathrm{c}_{7} & \mathrm{c}_{8} & \\ -\mathrm{c}_{2} & \mathrm{c}_{1} & \mathrm{c}_{4} & -\mathrm{c}_{3} & \mathrm{c}_{6} & -\mathrm{c}_{5} & -\mathrm{c}_{8} & \mathrm{c}_{7} & \\ -\mathrm{c}_{3} & \mathrm{c}_{4} & \mathrm{c}_{1} & \mathrm{c}_{2} & \mathrm{c}_{7} & \mathrm{c}_{8} & & -\mathrm{c}_{5} & -\mathrm{c}_{6} \\ -\mathrm{c}_{4} & \mathrm{c}_{3} & \mathrm{c}_{2} & \mathrm{c}_{1} & \mathrm{c}_{8} & -\mathrm{c}_{7} & \mathrm{c}_{6} & -\mathrm{c}_{5} & \\ -\mathrm{c}_{5} & -\mathrm{c}_{6} & -\mathrm{c}_{7} & -\mathrm{c}_{8} & \mathrm{c}_{1} & \mathrm{c}_{2} & & \mathrm{c}_{3} & \mathrm{c}_{4} \\ -\mathrm{c}_{6} & \mathrm{c}_{5} & -\mathrm{c}_{8} & \mathrm{c}_{7} & -\mathrm{c}_{2} & & \mathrm{c}_{1} & -\mathrm{c}_{4} & \mathrm{c}_{3} \\ -\mathrm{c}_{7} & \mathrm{c}_{8} & \mathrm{c}_{5} & -\mathrm{c}_{6} & -\mathrm{c}_{3} & \mathrm{c}_{4} & \mathrm{c}_{1} & -\mathrm{c}_{2} \\ -\mathrm{c}_{8} & -\mathrm{c}_{7} & \mathrm{c}_{6} & \mathrm{c}_{5} & -\mathrm{c}_{4} & -\mathrm{c}_{3} & \mathrm{c}_{2} & \mathrm{c}_{1}\end{array}\right]$




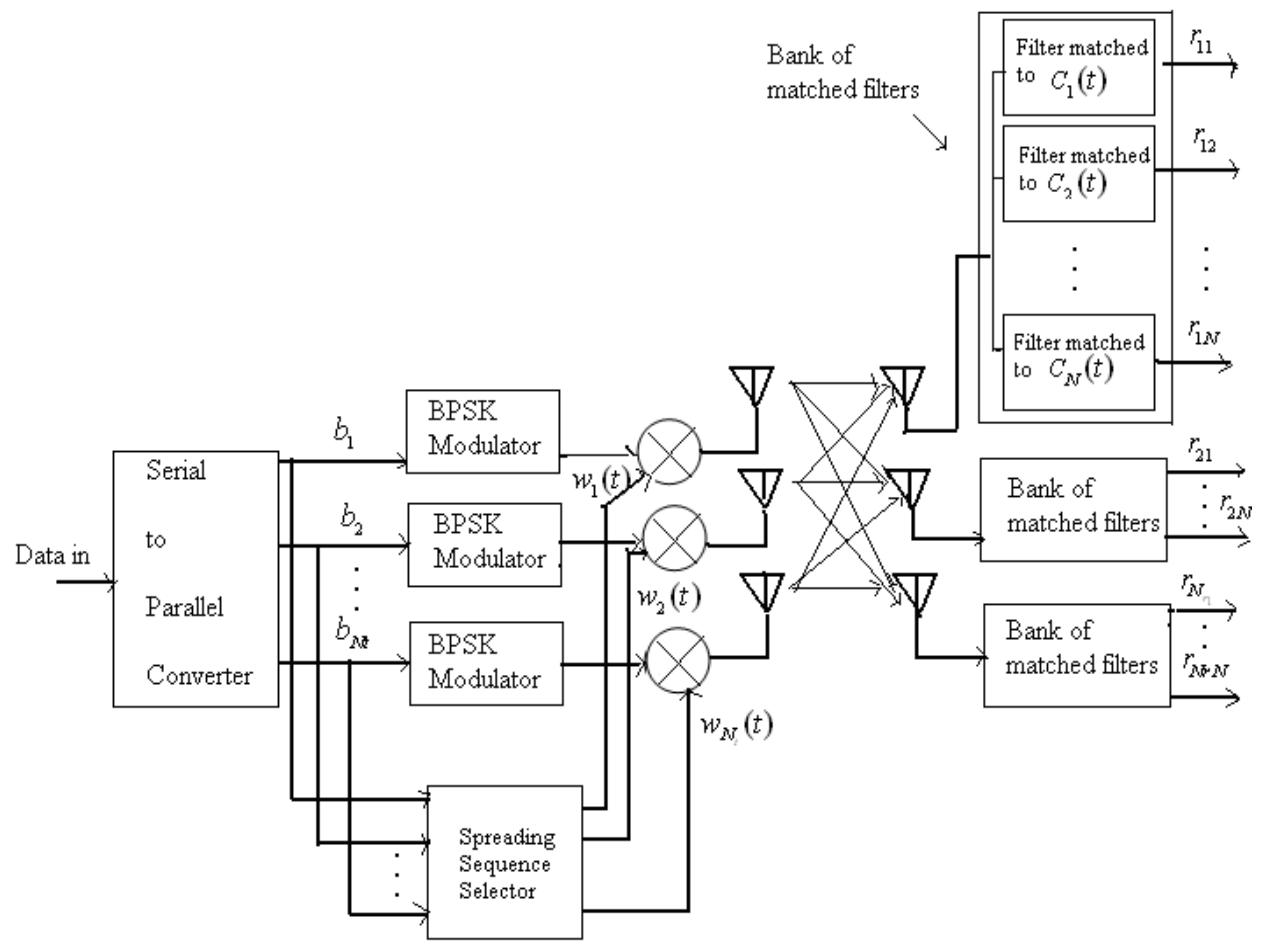

Fig 1: MIMO-CDMA system with STBC spreading permutation for 4 transmit and 4 receive antennas.

Here the columns of 1,5,8, and 6 of above matrix shown are assigned to columns 1,2,3,4 of TABLE II.

The received vector $\mathrm{r}=\mathrm{u}_{\mathrm{b}}+\mathrm{n}$,

Where $\mathrm{r}=\left[r_{11}, r_{12}, \ldots, r_{18}, \ldots, r_{21}, \ldots, r_{41}, \ldots, r_{48}\right]$ and

$$
\mathrm{n}=\left[n_{11}, n_{12}, \ldots, n_{18}, \ldots, n_{21}, \ldots, n_{41}, \ldots, n_{48}\right]
$$

where $\mathrm{u}_{\mathrm{b}}$ is the received data vector that depends on the transmitted data vector without noise. And $b=\left[b_{1}, b_{2}, b_{3}, b_{4}\right]$ in case of $4 \times 4$ antenna system.

For example if $\mathrm{m}=[0,0,0,1]$ then $\mathrm{b}=[-1,-1,-1,1]$ and

$\mathrm{u}_{\mathrm{b}}=\left[0,-\alpha_{11}, 0,0, \alpha_{41},-\alpha_{21},-\alpha_{31}, 0,0,-\alpha_{12}, 0,0, \alpha_{42},-\alpha_{22},-\alpha_{32}, 0,0,-\alpha_{13}, 0,0, \alpha_{43},-\alpha_{23},-\quad \alpha_{33}, 0,0,-\right.$ $\left.\alpha_{14}, 0,0, \alpha_{44},-\alpha_{24},-\alpha_{34}, 0\right]$

Maximum likely hood detection is performed to detect the data. And squared Euclidean distance is found between the received vector and all other possible received vectors and the value which is minimum will be taken as the transmitted message.

$$
\hat{b}=\min _{b}\left\|r-u_{b}\right\|^{2}
$$

The above expression finds the squared Euclidean distance between the received vector and all possible remaining vectors and the vector which gives the smallest distance that is the transmitted message. 
TABLE II. STBC PERMUTATION SPREADING TABLE FOR 4 TRANSMIT ANTENNAS

\begin{tabular}{|l|c|l|l|l|l|}
\hline Coset & $\begin{array}{c}\text { Message } \\
\text { Vectors }\end{array}$ & $w_{1}(t)$ & $w_{2}(t)$ & $w_{3}(t)$ & \multicolumn{1}{|c|}{$w_{4}(t)$} \\
\hline $\mathrm{M}_{1}$ & $\begin{array}{c}0000 \\
1111\end{array}$ & $\mathrm{C}_{1}(\mathrm{t})$ & $\mathrm{C}_{5}(\mathrm{t})$ & $\mathrm{C}_{8}(\mathrm{t})$ & $\mathrm{C}_{6}(\mathrm{t})$ \\
\hline $\mathrm{M}_{2}$ & $\begin{array}{l}0001 \\
1110\end{array}$ & $\mathrm{C}_{2}(\mathrm{t})$ & $\mathrm{C}_{6}(\mathrm{t})$ & $\mathrm{C}_{7}(\mathrm{t})$ & $\mathrm{C}_{5}(\mathrm{t})$ \\
\hline $\mathrm{M}_{3}$ & $\begin{array}{l}0010 \\
1101\end{array}$ & $\mathrm{C}_{3}(\mathrm{t})$ & $\mathrm{C}_{7}(\mathrm{t})$ & $\mathrm{C}_{6}(\mathrm{t})$ & $\mathrm{C}_{8}(\mathrm{t})$ \\
\hline $\mathrm{M}_{4}$ & $\begin{array}{l}0011 \\
1100\end{array}$ & $\mathrm{C}_{4}(\mathrm{t})$ & $\mathrm{C}_{8}(\mathrm{t})$ & $\mathrm{C}_{5}(\mathrm{t})$ & $\mathrm{C}_{7}(\mathrm{t})$ \\
\hline $\mathrm{M}_{5}$ & 0100 & $\mathrm{C}_{5}(\mathrm{t})$ & $\mathrm{C}_{1}(\mathrm{t})$ & $\mathrm{C}_{4}(\mathrm{t})$ & $\mathrm{C}_{2}(\mathrm{t})$ \\
\hline $\mathrm{M}_{6}$ & $\begin{array}{l}0101 \\
1010\end{array}$ & $\mathrm{C}_{6}(\mathrm{t})$ & $\mathrm{C}_{2}(\mathrm{t})$ & $\mathrm{C}_{3}(\mathrm{t})$ & $\mathrm{C}_{1}(\mathrm{t})$ \\
\hline $\mathrm{M}_{7}$ & 0110 & $\mathrm{C}_{7}(\mathrm{t})$ & $\mathrm{C}_{3}(\mathrm{t})$ & $\mathrm{C}_{2}(\mathrm{t})$ & $\mathrm{C}_{4}(\mathrm{t})$ \\
\hline $\mathrm{M}_{8}$ & $\begin{array}{l}0111 \\
1000\end{array}$ & $\mathrm{C}_{8}(\mathrm{t})$ & $\mathrm{C}_{4}(\mathrm{t})$ & $\mathrm{C}_{1}(\mathrm{t})$ & $\mathrm{C}_{3}(\mathrm{t})$ \\
\hline
\end{tabular}

\section{Simulation RESUltS}

MIMO-CDMA system with 4 transmit and 4 receive antennas are considered in this proposed technique and existing techniques .Simulation results for BER (bit error rate) performances are presented for $4 \times 4$ antenna system.

From Fig. 2 we see that MIMO-CDMA system employing STBC permutation spreading giving the better BER performance as compared to t-designs method, and conventional spreading also taken as reference. And here the proposed technique outperforms the conventional and t-designs.

From TABLE I, we can see that in t-design permutation spreading table, there is no code symmetry between different cosets, that leads to some degrees of freedom are lost, when MLD (maximum likelihood detection) is performed at the receiver. So that cause to slight increment of BER. But the system with STBC spreading, the permutation spreading table provides code symmetry between different cosets, so that gives better BER performance.

\section{CONCLUSIONS}

Code division multiple access technology, has been widely used in mobile communications, because of its high spectrum efficiency, low transmit power.

The T-designs Permutation Spreading method does not provide code symmetry so some sorts of degrees of freedom are lost in the squared Euclidean distance between different messages. The lack of code symmetry increases the BER.

The STBC technique create dependency between the data streams and provide performance improvement compared to conventional spreading. And code symmetry also provides by using space-time block codes. Space-time block coding is a simple and method for transmission using multiple transmit antennas in a wireless communication systems.

STBC codes have a very simple maximum-likelihood decoding algorithm which is only based on linear processing. They provide full diversity given by transmit and receive antennas. Bit error rate performance also improves compared to the conventional and t-designs permutation spreading techniques. 


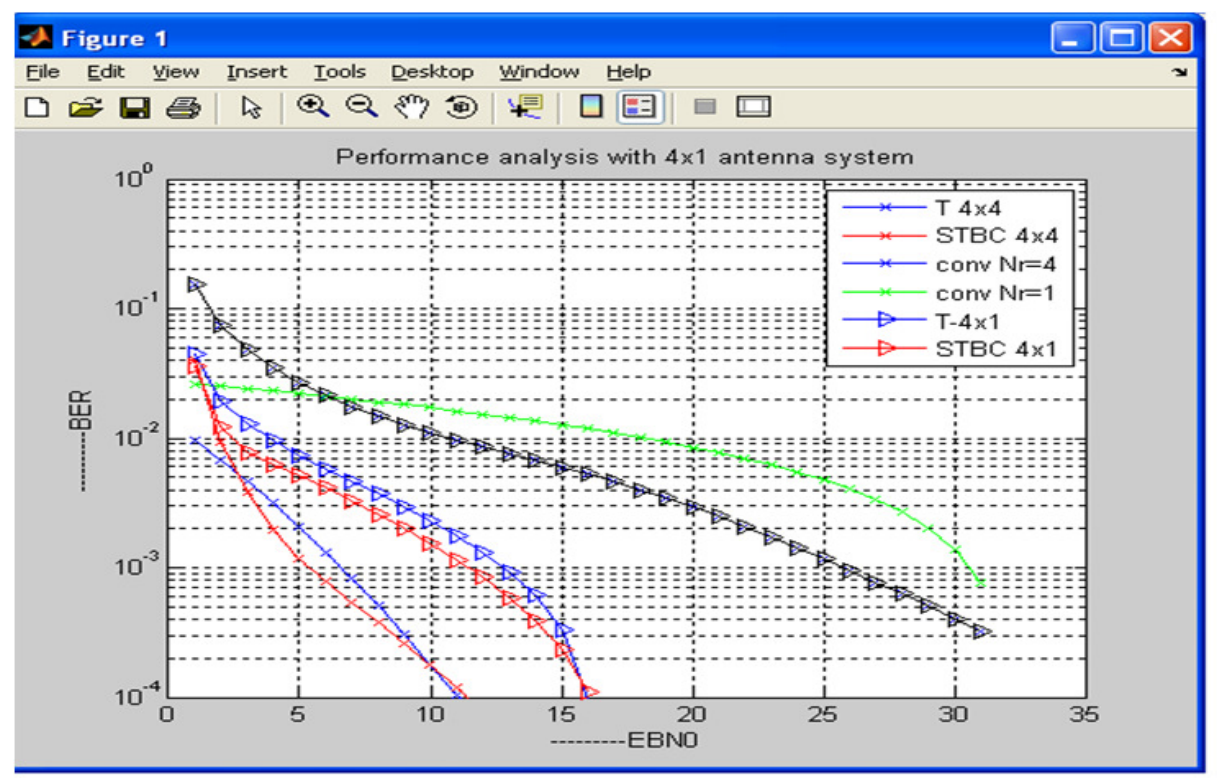

Fig. 2. BER performance for conventional, t-designs and STBC for $4 \mathrm{x} 1$ and $4 \mathrm{x} 4$ antenna system.

In this paper, MIMO-CDMA system with conventional, t-designs permutation spreading and STBC techniques has been analyzed. Both $4 \times 1$ and $4 \times 4$ systems are designed.

And in $4 \times 1$ antenna system proposed STBC systems have $1.2 \mathrm{~dB}$ gain over T-design permutation system.

The system with $4 \times 4$ antenna system proposed STBC systems have $0.2 \mathrm{~dB}$ gain over T-design permutation system.

\section{REFERENCES}

[1] Matthias stege and Fettweis G, "Multistratum-permutation codes for Multiple input multiple outputcommunication", IEEE Communication Letters, Vol. 21, June 2003, Page No. 774-782.

[2] Amours C.D, and Chouinard J, "Parity bit selected and permutation spreading for MIMO-CDMA systems, in Proc. IEEE Vehicular Technology, Apr 2007, Page No. 1475-1479.

[3] Adel Omar D, and Amours C.D, "Spreading strategies for MIMO-CDMA in presence of channel estimation errors and spatial correlation", Vehicular Technology Conference, Nov 2009, Page No. 15.

[4] Nordin Bin Ramli, Tetsuki Taniguchi and Yoshio Karasawa," Sub band Adaptive Array for MIMO STBC CDMA System”, IEICE Trans. Fundamentals, Vol. E90-A, Oct. 2007, Page No. 2309-2317.

[5] Min Shi, Amours C.D, "Design of Spreading Permutations for MIMO-CDMA based on Space-Time Block Codes", IEEE Communication Letters, Vol. 14, Jan 2010, Page No. 36-38.

[6] V. Tarokh, H. Jafarkhani, and A. R. Calderbank, "Space-time block codes from orthogonal designs," IEEE Trans. Inf. Theory, vol. 45, pp. 1456- 1467, July 1999. 